\title{
The rapid increase of circulating adiponectin in neonatal calves depends on colostrum intake
}

\author{
J. Kesser, ${ }^{*}$ M. Hill, ${ }^{\dagger} \dagger$ J. F. L. Heinz, ${ }^{*}$ C. Koch,† J. Rehage,‡ J. Steinhoff-Wagner, ${ }^{\star} \S$ H. M. Hammon,§ \\ B. Mielenz, ${ }^{\star} \S$ H. Sauerwein, ${ }^{*}$ and H. Sadri ${ }^{*}{ }^{1}$ \\ *Institute of Animal Science, Physiology \& Hygiene Unit, University of Bonn, 53115 Bonn, Germany \\ †Educational and Research Centre for Animal Husbandry, Hofgut Neumuehle, 67728 Muenchweiler a.d. Alsenz, Germany \\ ‡University of Veterinary Medicine Foundation, 30173 Hannover, Germany \\ §Leibniz Institute for Farm Animal Biology, 18196 Dummerstorf, Germany \\ \#Department of Clinical Science, Faculty of Veterinary Medicine, University of Tabriz, 5166616471 Tabriz, Iran
}

\begin{abstract}
Adiponectin, an adipokine, regulates metabolism and insulin sensitivity. Considering that the transplacental transfer of maternal proteins of high molecular weight is hindered in ruminants, this study tested the hypothesis that the blood concentration of adiponectin in neonatal calves largely reflects their endogenous synthesis whereby the intake of colostrum might modify the circulating concentrations. We thus characterized the adiponectin concentrations in neonatal and young calves that were fed either colostrum or formula. Three trials were performed: in trial 1, 20 calves were all fed colostrum for 3 $\mathrm{d}$, and then formula until weaning. Blood samples were collected on d 0 (before colostrum feeding), and on d 1, $3,11,22,34,43,52,70,90$, and 108 postnatum. In trial 2, 14 calves were studied for the first $4 \mathrm{~d}$ of life. They were fed colostrum $(\mathrm{n}=7)$ or formula $(\mathrm{n}=7)$, and blood samples were taken right after birth and before each morning feeding on $\mathrm{d} 2,3$, and 4 . In trial 3 , calves born preterm $(\mathrm{n}=7)$ or at term received colostrum only at $24 \mathrm{~h}$ postnatum. Blood was sampled at birth, and before and $2 \mathrm{~h}$ after feeding. Additionally, allantoic fluid and blood from 4 Holstein cows undergoing cesarean section were sampled. Adiponectin was quantified by ELISA. In trial 1, the serum adiponectin concentrations recorded on d 3 were 4.7-fold higher than before colostrum intake. The distribution of the molecular weight forms of adiponectin differed before and after colostrum consumption. In trial 2 , the colostrum group had consistently greater plasma adiponectin concentrations than the formula group after the first meal. In trial 3, the preterm calves tended to have lower concentrations of plasma adiponectin than the term calves
\end{abstract}

Received April 20, 2015.

Accepted June 26, 2015

${ }^{1}$ Corresponding author: hsadri@uni-bonn.de at birth and before and $2 \mathrm{~h}$ after feeding. Furthermore, the adiponectin concentrations were substantially lower in allantoic fluid than in the sera from neonatal calves and from cows at parturition. Our results show that calves are born with very low blood concentrations of adiponectin and placental transfer of adiponectin to the bovine fetus is unlikely. In conclusion, colostrum intake is essential for the postnatal increase of circulating adiponectin in newborn calves.

Key words: adiponectin, colostrum, milk-based formula, preterm-born, newborn calf

\section{INTRODUCTION}

Adiponectin is one of the most abundant adipocytokines in circulation and is well known for its insulinsensitizing effects and its role in regulating lipid and glucose metabolism (Kadowaki et al., 2006). It is mainly expressed in adipose tissue, and the circulating concentrations are inversely associated with adiposity and inflammation (Cnop et al., 2003). Adiponectin in blood occurs as multimeric complexes of different molecular weights (MW): as low MW trimer, medium MW hexamer, and as a high MW complex (HMW; Waki et al., 2003).

In human fetal blood, adiponectin is detectable from wk 24 of gestation (Kajantie et al., 2004); the concentrations in newborns are higher than those in adults and are positively associated with birth weight (Kotani et al., 2004). In addition, the available body of evidence suggests that the concentration and the MW distribution of adiponectin differ in preterm and term infants (Siahanidou et al., 2007). The mRNA expression of adiponectin and its receptor in human and rat placental tissue has also been reported (Caminos et al., 2005). Humans have a hemochorial placenta type that allows for the transplacental transfer of maternal proteins of high MW. In ruminants with an epitheliochorial placenta type, the transfer of such proteins is 
hindered and therefore neonates depend on the transfer of HMW proteins as known from the acquisition of passive immunity through colostral immune globulins (Barrington and Parish, 2001).

Milk, in particular colostrum, contains a wide range of different biologically active compounds that influence both immediate and long-term metabolism and health of the offspring (Blum and Hammon, 2000). The presence of adiponectin has been documented for human milk (Martin et al., 2006; Bronskỳ et al., 2012). The concentrations of adiponectin in mature human milk (around $20 \mathrm{ng} / \mathrm{mL}$; Bronskỳ et al., 2012) are far below the ones we recently reported for cow milk $(610 \mathrm{ng} / \mathrm{mL}$; Singh et al., 2014b), albeit the blood concentrations are comparable in the 1- to 2 -digit $\mu \mathrm{g} / \mathrm{mL}$ range in both species (Højlund et al., 2006; Singh et al., 2014a). In view of adiponectin's metabolic functions and of the expression of adiponectin receptor 1 in the small intestine of neonatal mice (Zhou et al., 2005), milk adiponectin may play an important role in infant development, both locally and systemically and may also exert a trajectory effect during later ages (Woo et al., 2012).

In consideration of the difference in placenta type and in milk concentrations between humans and ruminants, we hypothesized that in case of adiponectin, the blood concentration of adiponectin in neonatal ruminants will reflect their endogenous synthesis and might be influenced by intake of colostrum and milk. To test this hypothesis we used neonatal and young calves fed with either colostrum or formula and compared the time course of both the adiponectin plasma concentrations and the adiponectin MW distribution during the first days of life.

\section{MATERIALS AND METHODS}

\section{Trial 1}

Experimental Design, Animals, and Feeding. The experimental procedures performed in this study were in strict accordance with the German animal protection law and were approved by the relevant authority [Landesuntersuchungsamt Rheinland-Pfalz, Koblenz, Germany (G 11-20-026.)]. Twenty German Holstein calves (10 male and 10 female) were weighed and transferred to individual hutches with straw bedding when born. After $8 \mathrm{~d}$, the calves were kept in group pens equipped with an automatic feeding system (Vario Kombi, Förster-Technik GmbH, Engen, Germany) until d 70. All calves received colostrum from their dam 2 times daily for $3 \mathrm{~d}$, and then formula (Neumühle sauer, Trouw Nutrition Deutschland GmbH, Burgheim, Germany) from d 4 until weaning at $56 \mathrm{~d}$ with access to a pelleted starter concentrate and ad libitum access to hay and fresh water. The formula was reconstituted $(130 \mathrm{~g} / \mathrm{L}$ of water) and restricted to $6 \mathrm{~L}$ per calf and day (780 $\mathrm{g}$ of powder per calf/d). The study covered the period from birth until d 110 after birth and was conducted at the Educational and Research Centre for Animal Husbandry, Hofgut Neumuehle, Muenchweiler a.d. Alsenz, Germany.

Sample Collection. Blood samples were taken from a jugular vein immediately after birth and before colostrum consumption (d 0), and on d 1, 3, 11, 22, 34, 43, 52, 70, 90, and 108 after birth. Blood samples were centrifuged within $1 \mathrm{~h}$ at room temperature at 3,000 $\times g$ for $20 \mathrm{~min}$. The serum was obtained and frozen $\left(-20^{\circ} \mathrm{C}\right)$ until analysis.

\section{Trial 2}

Experimental Design, Animals, and Feeding. The experimental procedures performed in this study were in accordance with animal care guidelines and were approved by the relevant authorities of the State Mecklenburg-Vorpommern, Germany (LALLF M-V/ TSD/7221.3-1.1-014/07). The study was guided by the Leibniz Institute for Farm Animal Biology, Dummerstorf, Germany, and calves were kept in single boxes at the Research Station of the University of Rostock. The calves in the present study were used in a feeding trial to investigate glucose metabolism as previously described in detail (Steinhoff-Wagner et al., 2011a). Briefly, 14 male German Holstein calves were separated from their dams at birth and were transferred to individual, straw-bedded boxes with free access to water. Calves were randomly assigned to 2 experimental groups, each consisting of 7 animals: (1) colostrum (COL), and (2) formula (FOR). Calves were bottle-fed either pooled colostrum obtained from d 1, 2, and 3 after parturition or milk-based formula (Bergophor Futtermittelfabrik GmbH, Kulmbach, Germany) with comparable nutrient composition as colostrum on the first $3 \mathrm{~d}$ of life. On d 4, calves received either colostrum of d 3 or formula of $\mathrm{d} 3$ in groups COL and FOR, respectively. The daily amount of colostrum or formula fed was targeted to be $8 \%$ of BW on $\mathrm{d} 1$ and $10 \%$ of $\mathrm{BW}$ on $\mathrm{d} 2$ to 4 . The calves in both groups were slaughtered on d 4 of life, 2 $\mathrm{h}$ after the last feeding.

Sample Collection. Blood samples were taken from a jugular vein after birth, before first feeding of colostrum (d 1), from d 2 until d 4 before morning feeding and $2 \mathrm{~h}$ after feed intake on $\mathrm{d} 4$. Tubes containing $\mathrm{K}_{3}$ EDTA $(1.8 \mathrm{~g} / \mathrm{L}$ blood) were placed on ice and centrifuged at $1,500 \times g$ at $4^{\circ} \mathrm{C}$ for $20 \mathrm{~min}$ to harvest plasma. The plasma was stored at $-20^{\circ} \mathrm{C}$ until analyzed. 


\section{Trial 3}

Experimental Design, Animals, and Feeding. The animal ethical and study prerequisites were as described for trial 2. The calves were used in a study to investigate the maturation of endogenous glucose production in preterm and term calves. Details of this study were reported previously (Steinhoff-Wagner et al., 2011b). Briefly, 14 German Holstein calves, born preterm (PT; 6 male and 1 female) or at term $(\mathbf{T} ; 7$ male) were kept in individual boxes with straw bedding and free access to water. Calves in the $\mathrm{T}$ group were spontaneously born after normal gestation length. Preterm calves were delivered by caesarean section 9 $\mathrm{d}$ before the anticipated calving date. The calves in both groups were slaughtered $26 \mathrm{~h}$ after birth. They did not receive colostrum or milk during the first 24 $\mathrm{h}$ postnatum and were then fed with pooled colostrum from d 3 of lactation at $5 \%$ of BW, 2 h before slaughter.

Sample Collection. Blood samples were taken from a jugular vein immediately after birth, and before $(24 \mathrm{~h}$ after birth) and $2 \mathrm{~h}$ after final feeding. Preparation of plasma was as described for trial 2.

Additional samples from 4 healthy German Holstein cows undergoing caesarean section at the Clinic for Cattle, University of Veterinary Medicine (Hannover, Germany) were obtained. Allantoic fluid (AF) was collected during surgery, and blood samples from a jugular vein of the cows immediately thereafter. Blood was collected into EDTA tubes (Sarstedt AG and Co., Nümbrecht, Germany), centrifuged $(1,000 \times g, 15 \mathrm{~min}$, $4^{\circ} \mathrm{C}$ ) and the plasma obtained was stored at $-20^{\circ} \mathrm{C}$ until analysis.

\section{Analysis of Adiponectin Concentrations and MW Distribution}

Quantitative Assessment of Adiponectin by ELISA. Serum, plasma, colostrum, formula, and AF were assayed in duplicate for adiponectin using an inhouse developed bovine-specific ELISA that is based on a polyclonal rabbit antiserum generated against adiponectin purified from bovine serum (Mielenz et al., 2013). The original protocol of this ELISA was slightly modified, i.e., (a) for assaying colostrum, the microtiter plates were coated with whey prepared from colostrum (final dilution 1:20,000) instead of serum, (b) the antiserum was affinity-purified before use in all assays to exclude potential IgG binding antibodies, (c) the working dilution of the antiserum was $0.1 \mu \mathrm{g} / \mathrm{mL}$ and incubation was $3 \mathrm{~h}$ at $20^{\circ} \mathrm{C}$, and $(\mathrm{d})$ the peroxidaseconjugated secondary antibody (A1949, Sigma-Aldrich Chemie GmbH, Schnelldorf, Germany) was used at a 1:20,000 dilution. Serum and plasma can be used in the assay without difference. Assay accuracy was confirmed by linearity of diluted samples and parallelism of standard curve and dilution series. The measuring range of the assay was 0.07 to $1 \mathrm{ng} / \mathrm{mL}$ and the limit of detection was $0.03 \mathrm{ng} / \mathrm{mL}$. The intra- and interassay coefficients of variation were 7 and $9 \%$, respectively.

Western Blotting. To maintain the different multimer complexes, the samples were neither heat-denatured nor reduced before electrophoresis. The amount of adiponectin per lane that allows for optimal display of the different MW forms in each body fluid and in formula was initially assessed and the samples (serum, plasma, colostrum, and AF) subjected to electrophoresis and Western blotting were standardized for the same adiponectin concentrations based on prior ELISA results. The final amount of adiponectin loaded per lane to which all samples were standardized by diluting the samples with PBS was $0.5 \mathrm{ng}$. The diluted samples were mixed with sample buffer (final concentration: $0.064 M$ Tris $\mathrm{HCl} \mathrm{pH}$ 6.8, 1\% SDS, $0.01 \%$ bromophenol blue, $10 \%$ glycerol) and were centrifuged for 5 min at 10,000 $\times g$ and $4^{\circ} \mathrm{C}$ before loading on $8 \%$ SDS-PAGE gels. Proteins separated by SDS-PAGE were transferred onto a polyvinylidene difluoride membrane (GE Healthcare Europe, Freiburg, Germany) using tank blotting with the Criterion Blotter System (Bio-Rad Laboratories, Munich, Germany). After blotting, the membranes were blocked with Tris-buffered saline containing $0.05 \%$ Tween 20 (TBST) and 1\% Roti-Block (Carl Roth, Karlsruhe, Germany) for $60 \mathrm{~min}$ at room temperature. The membranes were exposed to the primary antibody (1 $\mu \mathrm{g} / \mathrm{mL}$, anti-bovine adiponectin polyclonal rabbit antiserum, same preparation as used in the ELISA) for $1 \mathrm{~h}$ at room temperature and washed 4 times with TBST. Likewise, the membranes were treated with the secondary antibody [i.e., a monoclonal anti-rabbit IgG $(\gamma$-chain specific) produced in mouse and conjugated with horseradish peroxidase (Sigma; A1949, 1:10,000)]. After washing, the immune complex was detected with an enhanced chemiluminescence detection system (GE Healthcare Europe GmbH, Amersham, UK) using the VersaDoc MP4000 imaging system with Image Lab software (Bio-Rad, Munich, Germany). The MW of the developed bands was assessed by comparison with a MW marker (Prestained Protein Marker, High Range, 12949, Cell Signaling Technology Inc., Danvers, MA).

\section{Statistical Analyses}

Data from trials 1, 2, and 3 were analyzed using the Mixed Model of SAS 9.2 (SAS Institute Inc., Cary, NC). In trial 1, the model included the effects of time, sex, and the interaction of sex and time as fixed effects and calf as random effect. The outcome of this preliminary 


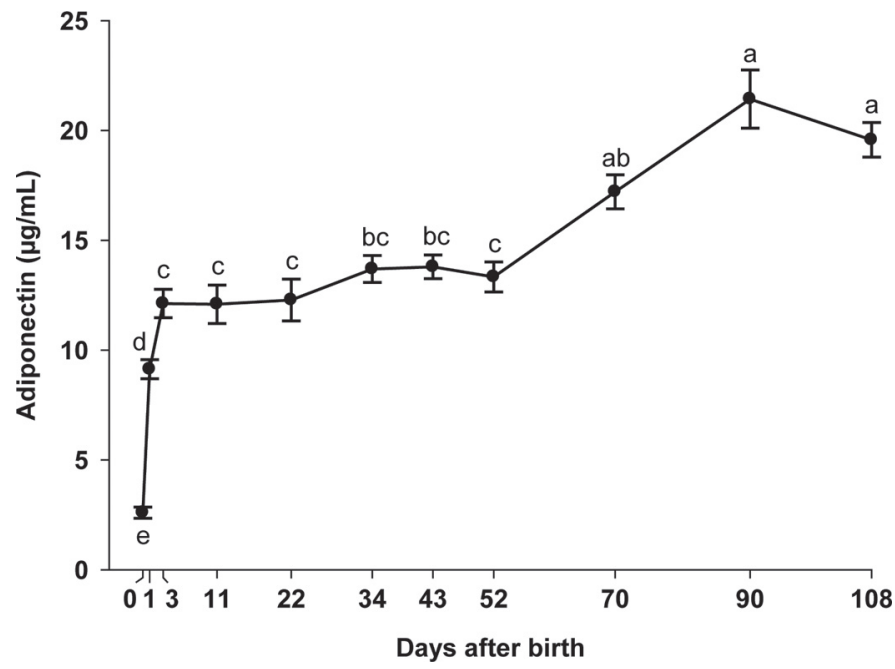

Figure 1. Concentrations of adiponectin in serum (means $\pm \mathrm{SEM}$, $\mu \mathrm{g} / \mathrm{mL})$ in Holstein calves $(\mathrm{n}=20)$ from birth until $108 \mathrm{~d}$ of life. Different letters $(\mathrm{a}-\mathrm{e})$ indicate differences $(P<0.05)$ between the time points.

statistical evaluation did not show any significant effect of sex or an interaction of sex and time on the serum adiponectin concentrations. Therefore, sex and the interaction of sex and time were disregarded as effects in the model for the final statistical analysis. Pearson correlation coefficients were derived to identify potential correlations between serum adiponectin concentrations at birth and birth BW. In trial 2, the model included diet (COL or FOR), sampling time point, and diet by time interaction as fixed effects, and calf as random effect. In trial 3, the model included the fixed effects of group $(\mathrm{PT}, \mathrm{T})$, time, and group $\times$ time, and the random effect of calf. A Tukey-Kramer adjustment was used to account for multiple comparisons. Results are presented as means \pm standard error of the mean. The threshold of significance was set at $P<0.05$; trends were declared at $0.05<P \leq 0.10$.

\section{RESULTS}

\section{Adiponectin Concentrations in Serum and AF}

The time course of the adiponectin serum concentrations in dairy calves during the first $108 \mathrm{~d}$ of life (trial 1 ) is shown in Figure 1. Serum adiponectin was changed during the course of the study $(P<0.01)$. Immediately after birth, and before colostrum intake, the concentrations of adiponectin were lowest as compared with all other sampling time points $(P<0.05)$. The adiponectin concentrations in serum increased 3.5- and 4.7-fold in the $\mathrm{d} 1$ and 3 samples compared with d 0 (before colostrum intake). Until d 52, the concentrations remained unchanged, but increased again thereafter until the end of the study on d 108 of life $(P<0.05)$. The serum adiponectin concentrations at birth and birth BW of calves $(41.9 \pm 0.82 \mathrm{~kg})$ were not correlated.

In Figure 2 the plasma concentrations of adiponectin in COL and FOR calves (trial 2) from birth to d 4 of life are shown. In the FOR group, the plasma adiponectin concentrations slightly increased from birth until 72 $\mathrm{h}$ thereafter $(P<0.05)$. Before colostrum consumption $(0 \mathrm{~h})$, adiponectin concentrations were also very low in the COL group, comparable with the FOR group, but were substantially increased at $24 \mathrm{~h}$ after colostrum intake $(P<0.05)$. From that time onward, the calves in the COL group had consistently greater $(P<0.05)$ blood adiponectin concentrations than the FOR calves (Figure 2). The plasma concentrations of adiponectin before and $2 \mathrm{~h}$ after feeding on $\mathrm{d} 4$ were not affected by time in both groups, but were also higher in COL calves than in FOR calves at both times $(P<0.05$; data not shown).

The PT calves from trial 3 tended $(P=0.10)$ to have lower concentrations of adiponectin than the $\mathrm{T}$ calves at birth, and before and $2 \mathrm{~h}$ after feeding on $\mathrm{d} 2$ of life (Figure 3). Plasma adiponectin concentrations did not change over time. Furthermore, no group by time interactions was observed for the plasma concentrations of adiponectin.

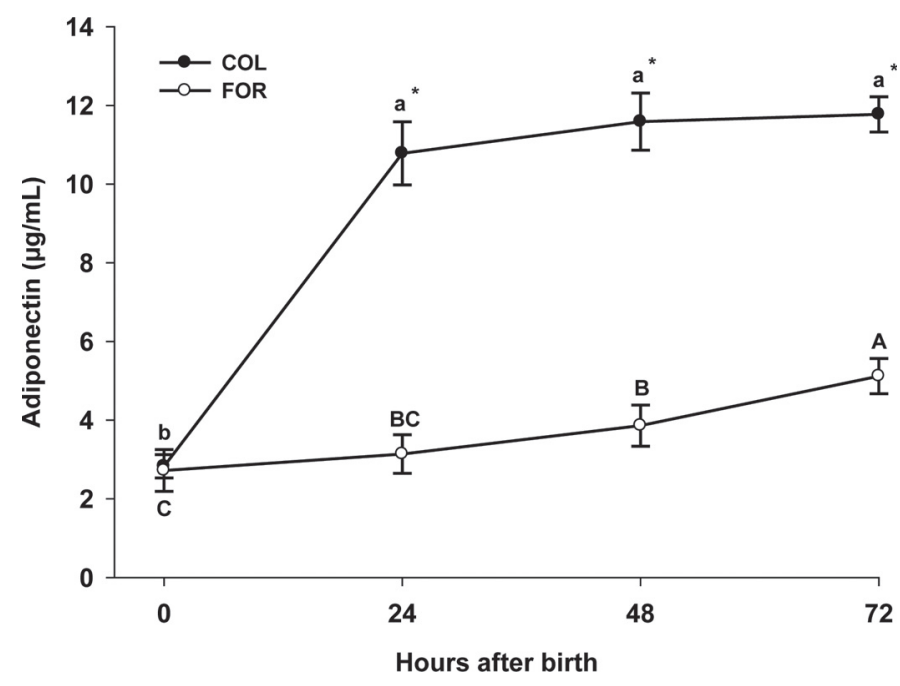

Figure 2. Concentrations of adiponectin in plasma (means $\pm \mathrm{SEM}$, $\mu \mathrm{g} / \mathrm{mL} ; \mathrm{n}=7$ per group) in calves fed either colostrum (COL) or formula (FOR) for $4 \mathrm{~d}$. Different lowercase letters indicate differences $(P<0.05)$ between the time points $(\mathrm{a}, \mathrm{b})$ in the COL calves. Different uppercase letters indicate differences $(P<0.05)$ between the time points $(\mathrm{A}-\mathrm{C})$ in the FOR calves. An asterisk $(*)$ indicates a significant difference $(P<0.05)$ between COL- and FOR-fed calves at a given time point. Significant effects $(P<0.001)$ were time, diet, and diet $\times$ time effects. 


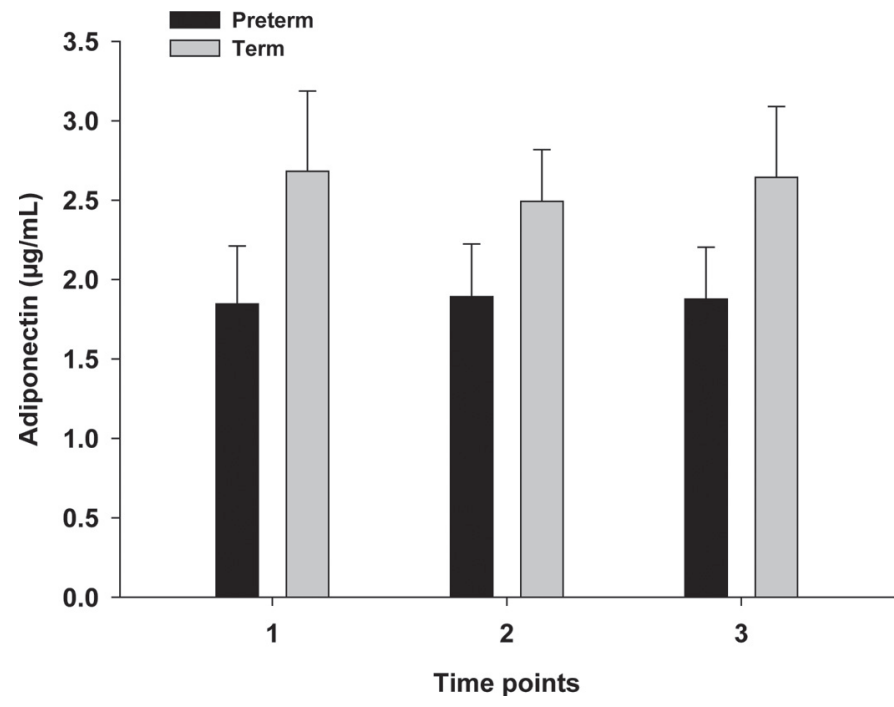

Figure 3. Concentrations of adiponectin in plasma (means \pm SEM, $\mu \mathrm{g} / \mathrm{mL}$ ) immediately after birth (1) and before (2) and $2 \mathrm{~h}$ after feeding on d 2 of life (3) in preterm and term-born calves. Time effect, $P$ $=0.90 ;$ group effect, $P=0.10$; group $\times$ time effect, $P=0.64$.

The adiponectin concentrations recorded in AF collected during caesarean section were $2.60 \pm 0.70 \mathrm{ng} /$ $\mathrm{mL}$ and thus far below the ones observed in neonatal calves $(2.55 \pm 0.16 \mu \mathrm{g} / \mathrm{mL}$; means from trials $1-3)$ and in cows at parturition $(19.8 \pm 0.70 \mu \mathrm{g} / \mathrm{mL}$, trial 4$)$.

\section{Adiponectin Concentrations in Colostrum and Formula}

The adiponectin concentrations in colostrum used in trials 1 and 2 were greater on d 1 than on d 2 and 3 , respectively (Table 1 ). The adiponectin content in the
Table 1. Mean adiponectin concentrations in colostrum and formula

\begin{tabular}{lc}
\hline Item & Adiponectin $(\mu \mathrm{g} / \mathrm{mL})$ \\
\hline Trial $1^{1}$ & \\
Colostrum & \\
d 1 & $75.9 \pm 4.19$ \\
d 3 & $3.32 \pm 0.30$ \\
Formula & 0.38 \\
Trials 2 and 3 & \\
Colostrum & \\
d 1 & 56.1 \\
d 2 & 19.9 \\
d 3 & 2.67 \\
Formula & \\
d 1 & 0.38 \\
d 2 & 0.36 \\
d 3 & 0.27 \\
\hline
\end{tabular}

${ }^{1}$ Colostrum data from trial 1 in which calves received colostrum from their own dams comprise 20 individual colostrums; all other adiponectin concentrations refer to pooled colostrum (trials 2 and 3 ) or pooled formula (trials 1 to 3 ) that was given to the calves.

formula was almost 200-fold lower than in d 1 colostrum in trial 1 and 165-fold lower in trial 2 (Table 1).

\section{Adiponectin Multimeric Complexes in Blood, Milk, and AF}

In trial 1, as displayed in Figure 4A, the adiponectin complexes differed in their distribution of HMW forms before and after colostrum consumption. Before colostrum intake, only faint bands were detected for the HMW isoforms of adiponectin in the serum, whereas after the intake of colostrum, the HMW complexes demonstrated a prominent band with a shift to the upper MW similar to the one in the corresponding colostrum samples. In trial 2, the same trend was observed in terms of the distribution of HMW adiponectin in the
A)

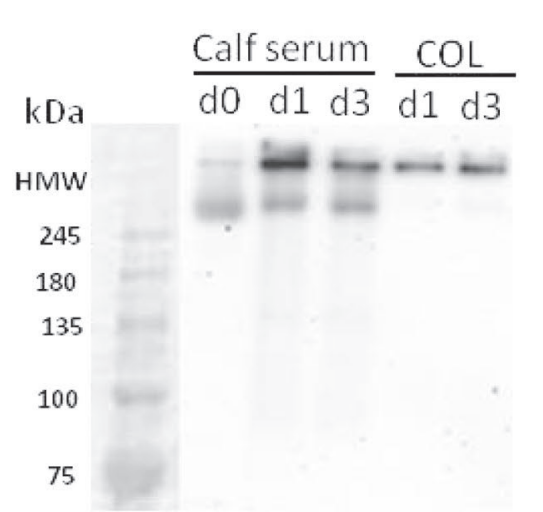

B)

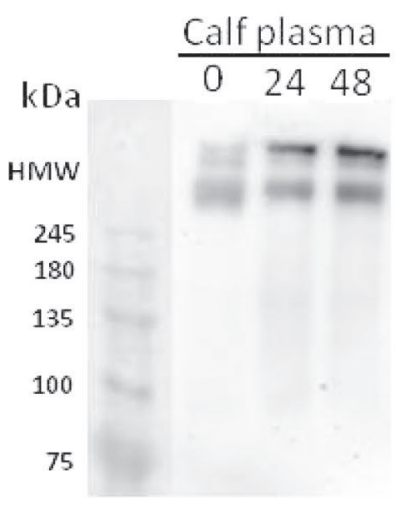

C)

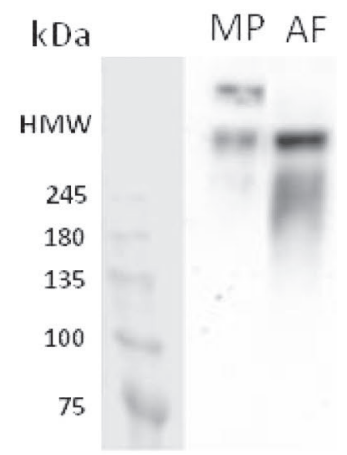

Figure 4. Representative Western blots of adiponectin multimeric complexes (A) in serum samples of calves from trial 1, before (d 0) and after receiving colostrum (d 1, 2, and 3) and corresponding colostrum (COL) samples (d 1 and 3); (B) in plasma samples of the calves from trial 2, before (0) and after receiving colostrum (24 and $48 \mathrm{~h}$ after birth); and (C) in maternal plasma (MP) and allantoic fluid (AF) from trial 4. HMW = high molecular weight form. 
plasma before and after colostrum consumption (Figure 4B). The adiponectin HMW forms were also present in maternal plasma and in AF (Figure 4C).

\section{DISCUSSION}

The present characterization of the ontogeny of circulating adiponectin in neonatal and young calves documents that colostrum plays a critical role for the transfer of adiponectin from the dam to the neonate in cattle. Assuming that the low blood adiponectin concentrations in calves at birth represent the calf's endogenous secretion and originate from adipose tissue, low concentrations were to be expected in view of the low body fat content in neonatal calves. The blood adiponectin concentrations increased 3- to 4-fold after the first colostrum consumption. The changes observed for the MW distribution of circulating adiponectin in calves after intake of colostrum provided also qualitative support for colostrum being the major source of adiponectin in newborn calves. In umbilical cord blood from human neonates, the adiponectin serum concentrations range between 20 to $60 \mu \mathrm{g} / \mathrm{mL}$ (Sivan et al., 2003) and are thus greater than in the newborn calves before colostrum intake reported herein. The higher adiponectin serum concentrations in human neonates point to a placental transfer of maternal adiponectin to the fetus. However, the adiponectin serum concentrations in human neonates reportedly exceed the maternal ones (Kotani et al., 2004; Dawczynski et al., 2014), suggesting fetal origin of adiponectin (Lindsay et al., 2003; Sivan et al., 2003; Corbetta et al., 2005). In contrast, the adiponectin plasma concentrations in the calves at birth (trials 1-3) were substantially lower than those measured in the cows undergoing caesarean section or from other cows at parturition as reported earlier (Mielenz et al., 2013; Singh et al., 2014a,b). In addition, the very low concentrations of adiponectin in the AF suggest that the placental transfer of adiponectin in cattle is unlikely or negligible. Nevertheless, the concordance of the HMW adiponectin in AF and in blood from newborn calves before colostrum feeding supports that bovine fetuses do endogenously produce adiponectin, albeit at a low level. The higher endogenous production of adiponectin during fetal life in humans as compared with cattle might be related by species differences in body fat content because human infants have the highest body fat levels of any mammalian species (around 16\%; Widdowson, 1950). Neonatal calves or lambs have body fat content of about $2 \%$ (Marple, 2003).

Human milk adiponectin concentrations have been reported to range from 4 to $88 \mathrm{ng} / \mathrm{mL}$ (Martin et al.,
2006). However, our present data about the adiponectin concentrations in bovine colostrum derived from the first $3 \mathrm{~d}$ of lactation ( 3 to $76 \mu \mathrm{g} / \mathrm{mL}$ ) demonstrate substantially higher concentrations than reported for human milk in the first week postpartum $(50 \mathrm{ng} / \mathrm{mL}$; Ley et al., 2012). Therefore, unlike human neonates, calves receive a significant portion of their circulating adiponectin from their mother's colostrum.

Following the adiponectin serum concentrations beyond the time of colostrum feeding in the calves from trial 1 , the values remained unchanged until d 52 , but increased gradually thereafter to concentrations similar to the ones reported for lactating dairy cows (Mielenz et al., 2013) or breeding bulls of similar age (Heinz et al., 2015) until d 90 of life. In view of the biological half-life of adiponectin in circulation that is reportedly about 75 min in mice (Halberg et al., 2009), a decrease of the plasma adiponectin concentrations in the COL group from trial 2 would be expected after the initial rise with colostrum feeding. Surprisingly, the adiponectin concentrations in plasma remained fairly constant and were maintained when the intake of colostrum and thus adiponectin ceased due to gut closure around 24 $\mathrm{h}$ postnatum; also, $72 \mathrm{~h}$ after birth, no decline in adiponectin was observed. Adiponectin has structural homology with complement factor C1q (Okamoto et al., 2000) and C1q-adiponectin complexes were detected in human blood (Nakatsuji et al., 2013). The ELISA used herein to quantify adiponectin has negligible cross reactivity $(<0.0001 \%)$ with the human $\mathrm{C} 1 \mathrm{q}$ protein and other proteins such as albumin and collagen (Mielenz et al., 2013); therefore, we can exclude interference of C1q or C1q-adiponectin complexes in the assay. Moreover, the concentrations of $\mathrm{C} 1 \mathrm{q}$ in bovine milk are very low (Rainard, 2003). The underlying mechanisms regulating plasma adiponectin concentrations in the neonatal calves are not yet known. It is likely that factors other than endogenous adiponectin secretion also affect the circulating concentrations of adiponectin in newborn calves. We thus speculate that the rate of turnover of colostral adiponectin might be slower as a compensatory effect to the lower rate of endogenous adiponectin production with regard to a very low percentage of body fat in neonatal calves (Marple, 2003). Nevertheless, in view of the consistently low concentrations in the FOR group compared with the COL group in trial 2 , colostrum might indeed be indispensable for an early induction of adiponectin synthesis in neonatal calves. Colostrum intake might also have triggered the secretion of adiponectin from brown adipose tissue; the expression of adiponectin has already been reported in brown adipose tissue of humans and rodents (Viengchareun et al., 2002; Iacobellis et al., 2013). The serum adiponec- 
tin concentrations in neonatal, prepubertal calves were not different between males and females; data on sex dependent variations of circulating adiponectin in human babies are contradictory (Ley et al., 2012). In our study, birth BW and serum adiponectin concentrations were not correlated. However, for humans, a positive correlation between adiponectin serum concentrations and birth BW was reported (Kotani et al., 2004).

Previous studies in human infants have shown that total adiponectin concentrations are significantly lower in preterm compared with full-term infants (Siahanidou et al., 2009) and this difference is probably due to decreased adiposity of preterm infants (Siahanidou et al., 2007). Adiponectin concentrations correlated positively with the degree of adiposity in neonates, whereas in adults inverse relationships are known (Kotani et al., 2004; Pardo et al., 2004; Tsai et al., 2004). In the current study, plasma adiponectin concentrations tended to be lower in PT calves compared with $\mathrm{T}$ calves. The calves in both groups received pooled colostrum from d 3 of lactation only $2 \mathrm{~h}$ before last blood sampling at $26 \mathrm{~h}$ of life. In both groups, no changes were observed in plasma concentrations of adiponectin $2 \mathrm{~h}$ after colostrum feeding compared with the values before feeding. Furthermore, the values measured were substantially lower than those observed in calves that received colostrum at birth (trials 1 and 2). Besides feeding colostrum with lower adiponectin concentrations, the timing of feeding (i.e., when gut closure occurred) is the most likely explanation for this difference. Taken together, adiponectin is unlikely to be transferred through the placental from the dam to the fetus in cattle. In contrast to human infants, fetal synthesis and secretion of adiponectin seem low in the bovine species. In confirmation of our working hypothesis, the blood concentrations of adiponectin in neonatal ruminants are indeed very low at birth but increase with intake of colostrum and milk. Besides increasing the circulating concentrations in the neonate, the high adiponectin concentrations in bovine colostrum and milk may also play a role for gut development because adiponectin receptors were already demonstrated both at the mRNA level and the protein level in intestinal tissue of fetal mice (Zhou et al., 2005) and humans (>9 mo of age; Bronskỳ et al., 2012). Moreover, as adiponectin is a glycoprotein, it might also have a role for pathogen protection in the gut, acting as growth promoter for genera of beneficial microflora (Gopal and Gill, 2000) and preventing adverse effects of bacterial toxins because adiponectin was demonstrated to bind bacterial lipopolysaccharide (Peake et al., 2006).

In conclusion, calves are born with very low blood concentrations of adiponectin and colostrum intake is crucial to supply blood adiponectin and may also be indispensable to trigger the endogenous adiponectin secretion in newborn calves.

\section{ACKNOWLEDGMENTS}

This study was supported by the German Research Foundation (Deutsche Forschungsgemeinschaft, DFG, Bonn, Germany) who funded the study by the grant HA 4372/5-1 (trials 2 and 3; Leibniz Institute for Farm Animal Biology, Dummerstorf, Germany). Johanna F. L. Heinz was recipient of a scholarship of the Theodor Brinkmann Graduate School of the Agricultural Faculty of the University of Bonn, Bonn, Germany.

\section{REFERENCES}

Barrington, G. M., and S. M. Parish. 2001. Bovine neonatal immunology. Vet. Clin. North Am. Food Anim. Pract. 17:463-476.

Blum, J. W., and H. Hammon. 2000. Colostrum effects on the gastrointestinal tract, and on nutritional, endocrine and metabolic parameters in neonatal calves. Livest. Sci. 66:151-159.

Bronskỳ, J., K. Mitrová, J. Nevoral, and J. Zámečnik. 2012. Immunoexpression of type- 1 adiponectin receptor in the human intestine. Cesk. Patol. 48:165-166.

Caminos, J. E., R. Nogueiras, R. Gallego, S. Bravo, S. Tovar, T. Garcia-Caballero, F. F. Casanueva, and C. Dieguez. 2005. Expression and regulation of adiponectin and receptor in human and rat placenta. J. Clin. Endocrinol. Metab. 90:4276-4286.

Cnop, M., P. J. Havel, K. M. Utzschneider, D. B. Carr, M. K. Sinha, E. J. Boyko, B. M. Retzlaff, R. H. Knopp, J. D. Brunzell, and S. E. Kahn. 2003. Relationship of adiponectin to body fat distribution, insulin sensitivity and plasma lipoproteins: Evidence for independent roles of age and sex. Diabetologia 46:459-469.

Corbetta, S., G. Bulfamante, D. Cortelazzi, V. Barresi, I. Cetin, G. Mantovani, S. Bondioni, P. Beck-Peccoz, and A. Spada. 2005. Adiponectin expression in human fetal tissues during mid- and late gestation. J. Clin. Endocrinol. Metab. 90:2397-2402.

Dawczynski, K., H. de Vries, J. F. Beck, E. Schleussner, S. Wittig, and H. Proquitte. 2014. Adiponectin serum concentrations in newborn at delivery appear to be of fetal origin. J. Pediatr. Endocrinol. Metab. 27:273-278.

Gopal, P. K., and H. S. Gill. 2000. Oligosaccharides and glycoconjugates in bovine milk and colostrum. Br. J. Nutr. 84(Suppl. 1):S69 S74.

Halberg, N., T. D. Schraw, Z. V. Wang, J. Y. Kim, J. Yi, M. P. Hamilton, K. Luby-Phelps, and P. E. Scherer. 2009. Systemic fate of the adipocyte-derived factor adiponectin. Diabetes 58:1961-1970.

Heinz, J. F., S. P. Singh, U. Janowitz, M. Hoelker, D. Tesfaye, K. Schellander, and H. Sauerwein. 2015. Characterization of adiponectin concentrations and molecular weight forms in serum, seminal plasma, and ovarian follicular fluid from cattle. Theriogenology $83: 326-333$.

Højlund, K., J. Frystyk, K. Levin, A. Flyvbjerg, J. Wojtaszewski, and H. Beck-Nielsen. 2006. Reduced plasma adiponectin concentrations may contribute to impaired insulin activation of glycogen synthase in skeletal muscle of patients with type 2 diabetes. Diabetologia 49:1283-1291.

Iacobellis, G., C. Di Gioia, L. Petramala, C. Chiappetta, V. Serra, L. Zinnamosca, C. Marinelli, A. Ciardi, G. De Toma, and C. Letizia. 2013. Brown fat expresses adiponectin in humans. Int. J. Endocrinol. 2013:126751.

Kadowaki, T., T. Yamauchi, N. Kubota, K. Hara, K. Ueki, and K. Tobe. 2006. Adiponectin and adiponectin receptors in insulin re- 
sistance, diabetes, and the metabolic syndrome. J. Clin. Invest. 116:1784-1792.

Kajantie, E., T. Hytinantti, P. Hovi, and S. Andersson. 2004. Cord plasma adiponectin: a 20 -fold rise between 24 weeks gestation and term. J. Clin. Endocrinol. Metab. 89:4031-4036.

Kotani, Y., I. Yokota, S. Kitamura, J. Matsuda, E. Naito, and Y. Kuroda. 2004. Plasma adiponectin levels in newborns are higher than those in adults and positively correlated with birth weight. Clin. Endocrinol. (Oxf.) 61:418-423.

Ley, S. H., A. J. Hanley, M. Sermer, B. Zinman, and D. L. O'Connor. 2012. Associations of prenatal metabolic abnormalities with insulin and adiponectin concentrations in human milk. Am. J. Clin. Nutr. 95:867-874.

Lindsay, R. S., J. D. Walker, P. J. Havel, B. A. Hamilton, A. A. Calder, and F. D. Johnstone. 2003. Adiponectin is present in cord blood but is unrelated to birth weight. Diabetes Care 26:2244-2249.

Marple, D. 2003. Fundamental concepts of growth. Pages 9-19 in Biology of Growth of Domestic Animals. C. G. Scanes, ed. Iowa State University Press, Ames.

Martin, L. J., J. G. Woo, S. R. Geraghty, M. Altaye, B. S. Davidson, W. Banach, L. M. Dolan, G. M. Ruiz-Palacios, and A. L. Morrow. 2006. Adiponectin is present in human milk and is associated with maternal factors. Am. J. Clin. Nutr. 83:1106-1111.

Mielenz, M., B. Mielenz, S. P. Singh, C. Kopp, J. Heinz, S. Haussler, and H. Sauerwein. 2013. Development, validation, and pilot application of a semiquantitative Western blot analysis and an ELISA for bovine adiponectin. Domest. Anim. Endocrinol. 44:121-130.

Nakatsuji, H., H. Kobayashi, K. Kishida, T. Nakagawa, S. Takahashi, H. Tanaka, S. Akamatsu, T. Funahashi, and I. Shimomura. 2013. Binding of adiponectin and $\mathrm{C} 1 \mathrm{q}$ in human serum, and clinical significance of the measurement of C1q-adiponectin/total adiponectin ratio. Metabolism 62:109-120.

Okamoto, Y., Y. Arita, M. Nishida, M. Muraguchi, N. Ouchi, M. Takahashi, T. Igura, Y. Inui, S. Kihara, T. Nakamura, S. Yamashita, J. Miyagawa, T. Funahashi, and Y. Matsuzawa. 2000. An adipocyte-derived plasma protein, adiponectin, adheres to injured vascular walls. Horm. Metab. Res. 32:47-50.

Pardo, I. M., B. Geloneze, M. A. Tambascia, and A. A. Barros-Filho. 2004. Hyperadiponectinemia in newborns: Relationship with leptin levels and birth weight. Obes. Res. 12:521-524.

Peake, P. W., Y. Shen, L. V. Campbell, and J. A. Charlesworth. 2006. Human adiponectin binds to bacterial lipopolysaccharide. Biochem. Biophys. Res. Commun. 341:108-115.

Rainard, P. 2003. The complement in milk and defense of the bovine mammary gland against infections. Vet. Res. 34:647-670.

Siahanidou, T., H. Mandyla, G. P. Papassotiriou, I. Papassotiriou, and G. Chrousos. 2007. Circulating levels of adiponectin in preterm infants. Arch. Dis. Child. Fetal Neonatal Ed. 92:F286-F290.
Siahanidou, T., A. Margeli, M. Garatzioti, M. Davradou, F. Apostolakou, I. Papassotiriou, and H. Mandyla. 2009. Disparity in circulating adiponectin multimers between term and preterm infants. J. Perinat. Med. 37:683-688.

Singh, S. P., S. Haussler, J. J. Gross, F. J. Schwarz, R. M. Bruckmaier, and H. Sauerwein. 2014b. Short communication: Circulating and milk adiponectin change differently during energy deficiency at different stages of lactation in dairy cows. J. Dairy Sci. 97:1535-1542.

Singh, S. P., S. Haussler, J. Heinz, B. Saremi, B. Mielenz, J. Rehage, S. Dänicke, M. Mielenz, and H. Sauerwein. 2014a. Supplementation with conjugated linoleic acids extends the adiponectin deficit during early lactation in dairy cows. Gen. Comp. Endocrinol. 198:13-21.

Sivan, E., S. Mazaki-Tovi, C. Pariente, Y. Efraty, E. Schiff, R. Hemi, and H. Kanety. 2003. Adiponectin in human cord blood: Relation to fetal birth weight and gender. J. Clin. Endocrinol. Metab. 88:5656-5660.

Steinhoff-Wagner, J., S. Gors, P. Junghans, R. M. Bruckmaier, E. Kanitz, C. C. Metges, and H. M. Hammon. 2011a. Intestinal glucose absorption but not endogenous glucose production differs between colostrum- and formula-fed neonatal calves. J. Nutr. 141:48-55.

Steinhoff-Wagner, J., S. Gors, P. Junghans, R. M. Bruckmaier, E. Kanitz, C. C. Metges, and H. M. Hammon. 2011b. Maturation of endogenous glucose production in preterm and term calves. J. Dairy Sci. 94:5111-5123.

Tsai, P. J., C. H. Yu, S. P. Hsu, Y. H. Lee, C. H. Chiou, Y. W. Hsu, S. C. Ho, and C. H. Chu. 2004. Cord plasma concentrations of adiponectin and leptin in healthy term neonates: Positive correlation with birth weight and neonatal adiposity. Clin. Endocrinol. (Oxf.) 61:88-93.

Viengchareun, S., M. C. Zennaro, L. Pascual-Le Tallec, and M. Lombes. 2002. Brown adipocytes are novel sites of expression and regulation of adiponectin and resistin. FEBS Lett. 532:345-350.

Waki, H., T. Yamauchi, J. Kamon, Y. Ito, S. Uchida, S. Kita, K. Hara, Y. Hada, F. Vasseur, P. Froguel, S. Kimura, R. Nagai, and T. Kadowaki. 2003. Impaired multimerization of human adiponectin mutants associated with diabetes. Molecular structure and multimer formation of adiponectin. J. Biol. Chem. 278:40352-40363.

Widdowson, E. M. 1950. Chemical composition of newly born mammals. Nature 166:626-628.

Woo, J. G., M. L. Guerrero, F. Guo, L. J. Martin, B. S. Davidson, H. Ortega, G. M. Ruiz-Palacios, and A. L. Morrow. 2012. Human milk adiponectin affects infant weight trajectory during the second year of life. J. Pediatr. Gastroenterol. Nutr. 54:532-539.

Zhou, Y., X. Sun, L. Jin, T. Stringfield, L. Lin, and Y. Chen. 2005. Expression profiles of adiponectin receptors in mouse embryos. Gene Expr. Patterns 5:711-715. 